\title{
Rosalind Franklin and her legacy in structural biology; the TMV chapter Gerald Stubbs ${ }^{1}$, Joseph Orgel $^{2}$ \\ ${ }^{1}$ Vanderbilt University ${ }^{2}$ No affiliation given gerald.stubbs@vanderbilt.edu
}

Rosalind Franklin moved from King's College to Birkbeck College in 1953, shortly after her beautiful and now famous diffraction patterns from DNA had been used to determine the DNA structure, and began to work on tobacco mosaic virus (TMV). She brought to TMV the same passion, determination, experimental genius, and insight that she had applied to DNA. At Birkbeck, she assembled a talented group of young scientists, Aaron Klug, Kenneth Holmes, and John Finch. Together they took TMV from a novelty (albeit a very important novelty, as the first virus to be discovered, isolated, and used in countless innovative and trail-blazing investigations) to a viable structural project, and laid the groundwork that would eventually lead to the determination of its structure in molecular detail.

The TMV project continued, first in Ken Holmes's lab, and then in the lab of GS, Holmes's postdoc. The detailed structure published in 1989, 31 years after Rosalind Franklin's death, confirmed numerous results from her work, and reminds us of both her genius and her vision. 